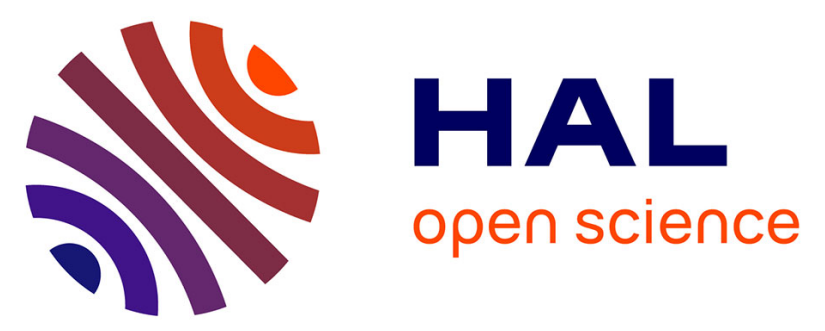

\title{
Assessment of platelet function on the routine coagulation analyzer Sysmex CS-2000i
}

Corinne Frere, Katsushi Kobayashi, Claire Dunois, Jean Amiral, Pierre-Emmanuel Morange, Marie-Christine Alessi

\section{> To cite this version:}

Corinne Frere, Katsushi Kobayashi, Claire Dunois, Jean Amiral, Pierre-Emmanuel Morange, et al.. Assessment of platelet function on the routine coagulation analyzer Sysmex CS-2000i. Platelets, 2018, 29 (1), pp.95-97. 10.1080/09537104.2017.1353683 . hal-01745795

\section{HAL Id: hal-01745795 \\ https://hal.science/hal-01745795}

Submitted on 11 Apr 2018

HAL is a multi-disciplinary open access archive for the deposit and dissemination of scientific research documents, whether they are published or not. The documents may come from teaching and research institutions in France or abroad, or from public or private research centers.
L'archive ouverte pluridisciplinaire HAL, est destinée au dépôt et à la diffusion de documents scientifiques de niveau recherche, publiés ou non, émanant des établissements d'enseignement et de recherche français ou étrangers, des laboratoires publics ou privés. 
Assessment of platelet function on the routine coagulation analyzer Sysmex CS-2000i

Corinne Frère, Katsushi Kobayashi, Claire Dunois, Jean Amiral, Pierre-Emmanuel Morange \& MarieChristine Alessi

\begin{abstract}
Background: Light transmission aggregometry (LTA) is considered as the gold standard for testing platelet function in the setting of both platelet disorders suspicion and response to antiplatelet therapy evaluation. LTA requires however specialized equipment, substantial blood sample volumes, is technically challenging and time-consuming. Aim: To evaluate an automated platelet aggregation method performed on a routine coagulation analyzer Sysmex CS-2000i. Methods: 46 patients presenting a bleeding syndrome and 62 patients with acute coronary syndrome receiving dual antiplatelet therapy were studied in total. Platelet aggregations were performed on CS-2000i equipped with a dedicated software and on APACT-4004 (Elitech, France) as the reference instrument. Aggregation was measured by monitoring the changes in light absorbance occurring in response to ADP $2.5,5$ and $10 \mu \mathrm{M}$, collagen $3.3 \mu \mathrm{g} / \mathrm{mL}$, epinephrin $10 \mu \mathrm{M}$, ristocetin $1.25 \mathrm{mg} / \mathrm{mL}$ and arachidonic acid 0.5 $\mathrm{mg} / \mathrm{mL}$ in platelet rich plasma (PRP). PRP were tested simultaneously on both CS-2000i and APACT-4004 devices. Platelet stirred speed were $800 \mathrm{rpm}$ for both instruments. Results: Significant correlations were observed between CS-2000i and LTA after all stimulations ( $\mathrm{p}<$ 0.001). Patients presenting a bleeding syndrome had similar aggregation profiles with both methods. A single patient presented a severe platelet disorder (Glanzmann Thrombasthenia) and its PRP showed defective aggregation in response to all agonists except ristocetin with both instruments. Finally, the inter-agreement rates for CS-2000i and APACT-4004 to detect low responders to thienopyridines or aspirine were strong (weighted kappa> 0.70). Conclusion: Platelet aggregation on the routine coagulation analyzer CS-2000i is an easily accessible, handy, reliable, standardized, and rapid tool to assess platelet function which allows to skirt most of the LTA limitations.
\end{abstract}

Laboratory investigations of platelet function are currently recommended in patients with bleeding symptoms suggestive of primary hemostatic disorders when thrombocytopenia and von Willebrand disease (VWD) have been excluded [Cattaneo M, Cerletti C, Harrison P, Hayward CPM, Kenny D, Nugent D, Nurden P, Rao AK, Schmaier AH, Watson SP, Lussana F, Pugliano MT, Michelson AD. Recommendations for the standardization of light transmission aggregometry: A consensus of the working party from the platelet physiology subcommittee of SSC/ISTH. J Thromb Haemost JTH 2013.]. Platelet function tests are also useful to assess both thienopyridines and aspirin responses in acute coronary syndrome (ACS) patients in some cases [Le Quellec S, Bordet J-C, Negrier C, Dargaud Y. Comparison of current platelet functional tests for the assessment of aspirin and clopidogrel response. A review of the literature. Thromb Haemost 2016;116:638-650]. The PFA-100 and PFA-200 are used in most hospitals and were demonstrated to be highly sensitive for VWD and severe platelet defects, but sometimes insensitive for mild disorders such as storage pool disease and Hermansky-Pudlak syndrome. The multiplate platelet function analyzer is also used in some laboratories, particularly to tailor antiplatelet therapy. However, the light transmission aggregometry (LTA) remains the "gold standard" method for platelet function exploration 
[Born GV, Cross MJ. The aggregation of blood platelets. J Physiol 1963;168:178-195]. Using an optical aggregometer with a fixed wavelength spectrophotometer, LTA evaluates increase in transmitted light when aggregation occurs under stirring conditions in platelet-rich plasma (PRP) following stimulation with a platelet agonist. LTA presents, however, some limitations: it requires both specialized equipment and substantial blood sample volumes, it is technically challenging and time-consuming, and finally it lacks standardization [Cattaneo M, Cerletti C, Harrison P, Hayward CPM, Kenny D, Nugent D, Nurden P, Rao AK, Schmaier AH, Watson SP, Lussana F, Pugliano MT, Michelson AD. Recommendations for the standardization of light transmission aggregometry: A consensus of the working party from the platelet physiology subcommittee of SSC/ISTH. J Thromb Haemost JTH 2013; Breddin HK. Can platelet aggregometry be standardized? Platelets 2005;16:151-158]. Consequently, very few hemostasis laboratories undertake this analysis and patients must often be referred to specialized centers for LTA investigation, which is inconvenient to the patients and sometimes delays the diagnosis and treatment. The development of new technologies to assess platelet function more easily and less costly appears thus as necessary. Recently, in order to automate platelet aggregation testing, an analytical procedure was developed with dedicated software on the CS-2000i coagulation analyzer (Sysmex Corporation, Japan) [ 5 Lawrie AS, Kobayashi K, Lane PJ, Mackie IJ, Machin SJ. The automation of routine light transmission platelet aggregation. Int J Lab Hematol 2014;36:431-438]. The aim of the present study was to evaluate this automated platelet aggregation method and to compare it to a reference LTA method.

Between January and May 2016, two different groups of patients were prospectively included in the study. The first group was constituted by patients not suffering from a VWD but presenting a history of bleeding or bleeding symptoms suggestive of platelet disorders as defined by petechiae, bruising, and mucosal bleeding such as gingival hemorrhage, epistaxis, and menorrhagia and referred to the "Centre d'Exploration des Pathologies Hémorragiques et Thrombotiques" (La Timone Hospital, Marseille, France) for LTA investigation. The second group was constituted by patients suffering from an ACS and receiving dual antiplatelet therapy (aspirin $100 \mathrm{mg}$ and clopidogrel $75 \mathrm{mg}$ once a day) and referred to our laboratory for antiplatelet therapy tailoring. Venous blood samples were collected after a short rest period by sterile venipuncture in vacutainer tubes (BD Life Science, Le Pont de Claix, France) filled to capacity containing buffered sodium citrate $0.105 \mathrm{M}$ (approximately $3.2 \%$ ) with a whole blood-to-anticoagulant ratio of 9:1. Samples were obtained with informed consent from all subjects. PRP and platelet-poor plasma (PPP) were prepared according to the platelet physiology subcommittee of SSC/ISTH recommendations for the standardization of LTA [Cattaneo M, Cerletti C, Harrison P, Hayward CPM, Kenny D, Nugent D, Nurden P, Rao AK, Schmaier AH, Watson SP, Lussana F, Pugliano MT, Michelson AD. Recommendations for the standardization of light transmission aggregometry: A consensus of the working party from the platelet physiology subcommittee of SSC/ISTH. J Thromb Haemost JTH 2013]. Briefly, the sample tubes were mixed by gentle inversion before centrifugation at $200 \mathrm{~g}$ for $10 \mathrm{~min}$ at ambient temperature (approximately $20-22^{\circ} \mathrm{C}$ ). The resultant PRP was aspirated using plastic pipettes and transferred to polypropylene tubes capped and kept at ambient temperature until testing. The primary sample tube was centrifuged once again at $1500 \mathrm{~g}$ for 15 min at ambient temperature to produce PPP, which was removed as described for the PRP. Platelet counts were then performed on the PPP and PRP using a Sysmex XN analyzer (Sysmex, Kobe, Japan) and all patients included in the study had a PRP platelet count $>150 \mathrm{G} / \mathrm{L}$. Platelet aggregations were performed on CS-2000i equipped with a dedicated software and on APACT-4004 (Elitech, France) as the reference instrument. Aggregation was measured by monitoring the changes in light absorbance occurring in response to ADP 2.5, 5, 
and $10 \mu \mathrm{M}$, collagen $3.3 \mu \mathrm{g} / \mathrm{mL}$, epinephrine $10 \mu \mathrm{M}$, ristocetin $1.25 \mathrm{mg} / \mathrm{mL}$, and arachidonic acid $0.5 \mathrm{mg} / \mathrm{mL}$ (all from HYPHEN BioMed, France) in PRP. PRP were tested

simultaneously on both CS-2000i and APACT-4004 devices. Platelet stirred speed was 800 rpm for both instruments. When using the CS-2000i instrument, after completion of reaction monitoring for all agonists for each PRP, the $100 \%$ light transmission reading is integrated with the measured and derived parameters from PRP reaction monitoring, and the aggregation traces are then viewed from the analyzer results file (Fig 1). The intra-serial imprecision (CV $\%$ ) of maximal intensity of platelet aggregation assessed with the CS-2000i instrument was lower than $5 \%$ for each agonist. Reference intervals were previously established in 30 healthy volunteers in our laboratory.

In total, 46 patients presenting bleeding symptoms suggestive of platelet disorders and 54 patients with ACS receiving dual antiplatelet therapy were studied. The 46 patients presenting bleeding symptoms suggestive of platelet disorders had similar aggregation profiles with both devices. A single patient presented a severe platelet disorder (Glanzmann Thrombasthenia) confirmed by flow cytometry and its PRP showed defective aggregation in response to all agonists except ristocetin with both instruments. All the other patients had both normal occlusion times and aggregation traces. Concerning patients with ACS receiving dual antiplatelet therapy, the classification of the values for both methods by using ADP, in relation to the presence or absence of high on thienopyridines platelet reactivity [Cuisset $\mathrm{T}$, Frere C, Quilici J, Gaborit B, Castelli C, Poyet R, Bali L, Morange P-E, Alessi M-C, Bonnet $\mathrm{J}$-L. Predictive values of post-treatment adenosine diphosphate-induced aggregation and vasodilator-stimulated phosphoprotein index for stent thrombosis after acute coronary syndrome in clopidogrel-treated patients. Am J Cardiol 2009;104:1078-1082], 49 (91\%) of the 54 patient samples tested were concordant. Good significant agreement was observed between the results obtained by the two tests $(\kappa=0.706 ; P<0.0001)$. By using arachidonic acid, in relation to the presence or absence high on aspirin platelet reactivity [Cuisset $\mathrm{T}$, Frere C, Quilici J, Morange P-E, Camoin L, Bali L, Lambert M, Juhan-Vague I, Alessi M-C, Bonnet J-L. Relationship between aspirin and clopidogrel responses in acute coronary syndrome and clinical predictors of non-response. Thromb Res 2009;123:597-603], 50 (94\%) of the 53 patient samples tested were concordant. Good significant agreement was observed between the results obtained by the two tests $(\kappa=0.822 ; P<0.0001)$.

Significant correlations between the CS-2000i and APACT-4004 were observed after stimulation with ADP $2.5 \mu \mathrm{M}(r=0.79 ; P<0.0001), 5 \mu \mathrm{M}(r=0.92 ; P<0.0001)$, and $10 \mu \mathrm{M}$ $(r=0.8963 ; P<0.0001)$; collagen $3.3 \mu \mathrm{g} / \mathrm{mL}(r=0.92 ; P<0.0001)$; epinephrine $10 \mu \mathrm{M}$ $(r=0.94 ; P<0.0001)$; ristocetin $1.25 \mathrm{mg} / \mathrm{mL}(r=0.38 ; P=0.0099)$; and arachidonic acid $0.5 \mathrm{mg} / \mathrm{mL}(r=0.98 ; P<0.0001)$. Bland and Altman plots showed that $95 \%$ of the differences were located within acceptable range with all agonists, allowing to conclude that the two compared devices could be considered as consistent (Fig 2).

In conclusion, this new method presents some limitations: the preparation of PRP remains time-consuming and the method is not suitable in the case of thrombocytopenia. However, this method presents benefits that allow to skirt some LTA limitations: it is easily accessible, more standardized, and it constitutes a more rapid tool to assess platelet function. This automated platelet aggregation method would thus potentially allow numerous hemostasis laboratories that are not equipped with an aggregometer to undertake an assessment of platelet function abnormalities and responsiveness to antiplatelet drugs. 


\section{References}

Cattaneo M, Cerletti C, Harrison P, Hayward CPM, Kenny D, Nugent D, Nurden P, Rao AK, Schmaier AH, Watson SP, Lussana F, Pugliano MT, Michelson AD. Recommendations for the standardization of light transmission aggregometry: A consensus of the working party from the platelet physiology subcommittee of SSC/ISTH. J Thromb Haemost JTH 2013. Le

Quellec S, Bordet J-C, Negrier C, Dargaud Y. Comparison of current platelet functional tests for the assessment of aspirin and clopidogrel response. A review of the literature. Thromb Haemost 2016;116:638-650.

Born GV, Cross MJ. The aggregation of blood platelets. J Physiol 1963;168:178-195. Breddin HK. Can platelet aggregometry be standardized? Platelets 2005;16:151-158.

Lawrie AS, Kobayashi K, Lane PJ, Mackie IJ, Machin SJ. The automation of routine light transmission platelet aggregation. Int J Lab Hematol 2014;36:431-438.

Cuisset T, Frere C, Quilici J, Gaborit B, Castelli C, Poyet R, Bali L, Morange P-E, Alessi M$\mathrm{C}$, Bonnet J-L. Predictive values of post-treatment adenosine diphosphate-induced aggregation and vasodilator-stimulated phosphoprotein index for stent thrombosis after acute coronary syndrome in clopidogrel-treated patients. Am J Cardiol 2009;104:1078-1082.

Cuisset T, Frere C, Quilici J, Morange P-E, Camoin L, Bali L, Lambert M, Juhan-Vague I, Alessi M-C, Bonnet J-L. Relationship between aspirin and clopidogrel responses in acute coronary syndrome and clinical predictors of non response. Thromb Res 2009;123:597-603. 